\title{
SISTEM INFORMASI PERSEDIAAN STOK BAHAN BAKU TOKO KOPI DENGAN MENGGUNAKAN METODE WATERFALL
}

\author{
M Gilvy Langgawan Putra ${ }^{1}$, Muhammad Iqbal Firdaus ${ }^{2}$, Rizky Febrian Nur ${ }^{1}$, Dinda Aprelia Isabella ${ }^{1}$, \\ Ilham Saputra ${ }^{1}$, Putri Ayu Tri Ashshofiah ${ }^{1}$, dan Zainul Muafi ${ }^{1}$ \\ ${ }^{1}$ Jurusan Matematika dan Teknologi Informasi, Institut Teknologi Kalimantan \\ Email: gilvy.langgawan@lecturer.itk.ac.id \\ ${ }^{2}$ Program Studi Teknik Informatika, Universitas Islam Kalimantan MAB \\ Email: m.iqbalfirdaus@uniska-bjm.ac.id
}

\begin{abstract}
Inventory is an important thing that must be considered by companies because inventory can affect the process of meeting needs for customers. Puan Kopi is an MSME with a new coffee shop concept in Balikpapan. Currently, Puan Kopi does not have an information system that manages data collection and purchases of raw materials used in each branch of the shop. The management of data collection and purchasing of raw materials at Puan Kopi is currently still using open media and Microsoft Excel. This causes the emergence of several problems, namely the stock of goods is too little so that they run out of stock and excess stock of goods, causing a buildup of stock in warehouse storage. To overcome these problems, a raw material inventory information system is needed. With the Raw Material Inventory Information System, Puan Kopi can support its business activities in a sustainable manner by controlling the amount of raw material inventory according to the required needs. The methodology used in this study is the waterfall method. The research procedure starts from Requirement Definition, System and Software Design, Implementation and Unit Testing, Integration and System Testing, Operation and Maintenance and ends with drawing conclusions and suggestions.
\end{abstract}

Keyword: Raw Materials, Waterfall Method, Inventory, Puan Coffe, Information System

\section{PENDAHULUAN}

Pesatnya perkembangan teknologi saat ini menjadi membawa dampak dalam suatu hal pendidikan, perdagangan, organisasi dan masih banyak lagi (Anwar, 2018). Peranan dalam suatu Teknologi Informasi secara langsung maupun tidak langsung telah berdampak pada dunia bisnis. Pemanfaatan teknologi informasi pada suatu perusahaan dapat membantu menyelesaikan suatu pekerjaan dengan baik sehingga informasi yang didapatkan cepat, relevan serta akurat (Mumtahana, 2019).

Selain peranan teknologi informasi bagi suatu perusahaan, terdapat pula hal yang penting harus diperhatikan oleh perusahaan yaitu persediaan dari bahan baku. Persedian adalah peran penting yang perlu diperhatikan karena persediaan dapat mempengaruhi proses pemenuhan kebutuhan untuk pelanggan. Suatu perusahaan harus memiliki keputusan dan laporan yang tepat mengenai banyaknya jumlah pesanan dan waktu pemesanan bahan baku. Dengan keputusan dan laporan yang tepat, suatu perusahaan dapat mengurangi pembengkakan biaya pembelian bahan baku dan mengurangi kecenderungan kekurangan bahan baku.

Hal ini juga berlaku bagi Puan Kopi. Puan Kopi merupakan sebuah UMKM dengan membawa konsep coffee shop yang baru di Balikpapan. Puan Kopi didirikan oleh Arief Setiawan dan Rizal Zulmi. Puan Kopi memiliki visi yaitu "Menjadi kedai kopi yang fokus dengan sistem take away" serta 3 misi antara lain Puan Kopi berusaha untuk menyajikan kopi dengan berbagai varians ras dengan harga yang terjangkau dikalangan masyarakat dengan menggunakan sistem take away, menempatkan pelanggan sebagai prioritas dan memberikan pelayanan yang unggul dalam penyajian. Puan Kopi menawarkan rasa kopi dengan aneka rasa seperti kopi karamel, kopi hazelnut, kopi klepon, kopi 
coconut, kopi strawberry, kopi pandan serta juga ada menu kopi sesuai identitas Puan Kopi yaitu menu kopi tuan dan kopi puan. Saat ini Puan Kopi belum memiliki sistem informasi yang mengelola pendataan dan pembelian bahan baku yang digunakan pada setiap cabang kedai. Pengelolaan pendataan dan pembelian bahan baku pada Puan Kopi saat ini masih menggunakan suatu media buka dan microsoft excel. Permasalahan disebabkan oleh beberapa hal antara lain jumlah barang yang masih sangat sedikit hal ini mengalami kehabisan stok dan stok barang yang berlebih sehingga menimbulkan penumpukan stok barang di penyimpanan gudang.

Untuk mengatasi permasalahan tersebut maka dibutuhkan suatu Sistem Informasi persediaan pada bahan baku. Dengan adanya Sistem Informasi Persediaan Bahan Baku tersebut, Puan Kopi menunjang kegiatan bisnisnya secara berkelanjutan dengan mengontrol jumlah persedian bahan baku sesuai kebutuhan yang diperlukan.

\section{METODE PENELITIAN}

Pada penelitian ini menerapkan metode waterfall dalam pengembangan sistem informasi persediaan bahan baku. Adapun tahapan pada metode waterfall yaitu :

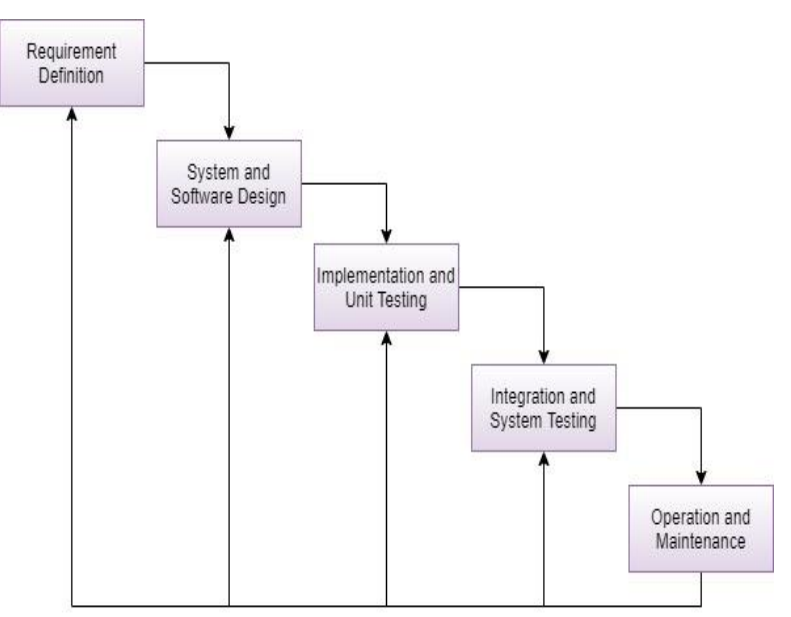

Gambar 1. Metode Pelaksanaan

a. Requirement Definition

Dalam tahap ini dilakukan diskusi dengan mitra untuk menganalisis dan menentukan kebutuhan sistem yang akan dikembangakan. Pada tahap ini pula ditentukan pula kebutuhan layanan, batasan dan tujuan pembuatan sistem yang nantinya akan berfungsi sebagai spesifikasi sistem. b. System and Software Design

Pada tahap ini akan dilakukan pengalokasian kebutuhan sistem dengan pembuatan arsitektur perangkat lunak (software) dan perangkat keras (hardware) secara keseluruhan. Pada tahap ini menghasilkan pemahaman sistem seutuhnya sebagai dasar pembuatan prototipe atau mulainya siayi sistem dasar dari suatu perangkat lunak.

c. Implementation and Unit Testing

Tahapan ini dilakukan realisasi dari perangkat yang telah di rancang menjadi serangkaian atau unit program. Untuk memenuhi spesifikasi program, setiap unit harus melakukan pengujian verifikasi untuk menyatakan telah memenuhi spesifikasi yang telah ditentukan.

d. Integration and System Testing

Sebelum perangkat lunak dikirimkan ke mitra, setiap unit program harus dilakukan pengujian untuk memastikan apakah sistem telah sesuai dengan kebutuhan perangkat lunak yang telah ditentukan.

e. Operation and Maintenance

Pada tahap ini biasanya memiliki tahapan yang panjang dimulai dengan pemasangan sistem hingga penggunaan sistem secara nyata. Tahap maitenance atau pemeliharaan digunakan untuk menemukan kesalahan yang tidak ditemukan pada tahap sebelumnya sehingga dapat meningkatkan implementasi sistem dan layanan sistem.

\section{HASIL DAN PEMBAHASAN}

Adapun hasil dan pembahasan berdasarkan hasil yang didapatkan oleh penulis.

\section{Lingkup Masalah}

Perangkat lunak SI PUAN merupakan perangkat lunak berbasis website yang akan digunakan oleh Puan Kopidalam pemesanan bahan baku kepada supplier yang telah terdaftar. Adapun lingkup masalah SI PUAN sebagai berikut:

1. Sistem mampu menampilkan fitur riwayat pembelian yaitu fitur yang menampilkan jejak transaksi yang telah dilakukan selama ini dari berbagai customer.

2. Sistem mampu menampilkan invoice sebagai bukti tanda pembayaran yang dimana dapat diakses oleh Puan Kopi maupun supplier. 
3. Sistem mampu memberikan rekomendasi jenis bahan baku sebagai kebutuhan informasi bagi Puan Kopi dan supplier yang bekerja sama.

4. Sistem mampu memberikan list dan location dari supplier dimana berfungsi sebagai informasi bagi Puan Kopi dalam memetakan supplier yang bekerja sama dengan mereka.

5. Sistem mampu memberikan rating yang dimana berfungsi sebagai bahan evaluasi bagi Puan Kopi dalam menjalankan bisnis mereka.

6. Sistem mampu melakukan pengecekan ketersediaan bahan baku yang dimana berfungsi sebagai kebutuhan informasi bagi Puan Kopi yang bekerja sama dengan kami dalam memenuhi kebutuhan bahan baku agar bisnis tetap dapat berjalan secara kontinu.

\section{Analisa Kebutuhan}

Berdasarkan lingkup masalah yang telah dijabarkan maka dirancang fungsi utama perangkat lunak sebagai berikut:

1. Sistem dapat menampilkan invoice sebagai bukti tanda pembayaran yang dimana dapat diakses oleh Puan Kopi maupun supplier.

2. Menampilkan fitur riwayat pembelian yaitu fitur yang menampilkan jejak transaksi yang telah dilakukan selama ini dari berbagai customer.

3. Sistem dapat menampilkan rekomendasi jenis bahan baku sebagai kebutuhan informasi bagi Puan Kopi dan supplier yang bekerja sama.

4. Sistem mampu memberikan list dan location dari supplier dimana berfungsi sebagai informasi bagi Puan Kopi dalam memetakan supplier yang bekerja sama dengan mereka.

5. Sistem mampu memberikan rating yang dimana berfungsi sebagai bahan evaluasi bagi Puan Kopi dalam menjalankan bisnis mereka.

6. Sistem mampu melakukan fitur pengecekan ketersediaan bahan baku yang dimana berfungsi sebagai kebutuhan informasi bagi PUAN Kopi yang bekerja sama dengan kami dalam memenuhi kebutuhan bahan baku agar bisnis tetap dapat berjalan secara kontinu.

Kebutuhan fungsional dari SI PUAN yang didefinisikan berdasarkan kode fungsinya, kebutuhan fungsional dibagi berdasarkan aktor yang terlibat yang terdiri dari Leader, Administrator, Supplier, Pegawai, dan Pengguna Umum.
Tabel 1. Kebutuhan Fungsional Leader

\begin{tabular}{l|c}
\hline \multicolumn{1}{c|}{ Kode Fungsi } & Nama Fungsi \\
\hline SRS_F-SI PUAN-002 & Menampilkan daftar supplier \\
\hline SRS_F-SI PUAN-003 & Menampilkan lokasi supplier \\
\hline SRS_F-SI PUAN-004 & Melihat ketersedian bahan baku \\
\hline SRS_F-SI PUAN-005 & Menampilkan invoice \\
\hline SRS_F-SI PUAN-006 & Menampilkan riwayat pembelian \\
\hline SRS_F-SI PUAN-007 & Menampilkan rating \\
\hline SRS_F-SI PUAN-030 & Logout \\
\hline
\end{tabular}

Tabel 2. Kebutuhan Fungsional Administrator

\begin{tabular}{l|c}
\hline \multicolumn{1}{c|}{ Kode Fungsi } & Nama Fungsi \\
\hline SRS_F-SI PUAN-008 & Menambahkan supplier \\
\hline SRS_F-SI PUAN-009 & Menghapus supplier \\
\hline SRS_F-SI PUAN-010 & Menghapus rating \\
\hline SRS_F-SI PUAN-011 & Menghapus kategori bahan baku \\
\hline SRS_F-SI PUAN-012 & Menambah jenis bahan baku \\
\hline SRS_F-SI PUAN-013 & Menghapus jenis bahan baku \\
\hline SRS_F-SI PUAN-014 & Mengubah data supplier \\
\hline SRS_F-SI PUAN-015 & $\begin{array}{c}\text { Menambahkan rekomendasi } \\
\text { bahan baku }\end{array}$ \\
\hline SRS_F-SI PUAN-006 & Menampilkan riwayat pembelian \\
\hline SRS_F-SI PUAN-030 & Logout \\
\hline
\end{tabular}

Tabel 3. Kebutuhan Fungsional Supplier

\begin{tabular}{c|c}
\hline Kode Fungsi & Nama Fungsi \\
\hline SRS_F-SI PUAN-016 & Melihat pesanan \\
\hline SRS_F-SI PUAN-017 & Mengirimkan invoice \\
\hline SRS_F-SI PUAN-018 & Menampilkan rating \\
\hline SRS_F-SI PUAN-006 & Menampilkan riwayat pembelian \\
\hline SRS_F-SI PUAN-030 & Logout \\
\hline
\end{tabular}

Tabel 4. Kebutuhan Fungsional Pegawai

\begin{tabular}{l|c}
\hline \multicolumn{1}{c|}{ Kode Fungsi } & Nama Fungsi \\
\hline SRS_F-SI PUAN-019 & Melihat rekomendasi bahan baku \\
\hline SRS_F-SI PUAN-020 & Memilih supplier \\
\hline SRS_F-SI PUAN-021 & Memilih kategori bahan baku \\
\hline SRS_F-SI PUAN-022 & $\begin{array}{c}\text { Menambahkan pesanan bahan } \\
\text { baku di keranjang }\end{array}$ \\
\hline SRS_F-SI PUAN-023 & $\begin{array}{c}\text { Menghapus pesanan bahan baku } \\
\text { di keranjang }\end{array}$ \\
\hline SRS_F-SI PUAN-024 & Memilih metode pengiriman \\
\hline SRS_F-SI PUAN-025 & Memilih metode pembayaran \\
\hline SRS_F-SI PUAN-026 & Melihat invoice \\
\hline SRS_F-SI PUAN-027 & $\begin{array}{c}\text { Memberikan rating kepada } \\
\text { supplier }\end{array}$ \\
\hline SRS_F-SI PUAN-006 & Melihat riwayat pembelian \\
\hline SRS_F-SI PUAN-030 & Logout \\
\hline
\end{tabular}

Tabel 5. Kebutuhan Fungsional Pengguna Umum

\begin{tabular}{c|c}
\hline Kode Fungsi & Nama Fungsi \\
\hline SRS_F-SI PUAN-028 & Registrasi \\
\hline SRS_F-SI PUAN-001 & Login \\
\hline SRS_F-SI PUAN-029 & Lupa assword \\
\hline
\end{tabular}


Website SI PUAN merupakan website yang menggunakan ruang lingkup berbasis web serta pengguna harus terhubung melalui internet untuk dapat mengakses website SI PUAN pada browser pengguna. Website SI PUAN dibangun menggunakan HTML dan CSS dengan bahasa pemrograman PHP serta menggunakan MySQL sebagai database. Website SI PUAN menggunakan lingkungan sistem sebagai berikut:

1. Server

1. Server menggunakan XAMPP v. 3.2.4

2. Sistem operasi menggunakan Windows 1064 bit.

3. RAM pada komputer server sebesar 4 GB DDR3

4. Processor Intel Core i3

5. Database Management System MySQL

2. Client

Client dapat mengakses pada website SI PUAN menggunakan sistem operasi Windows, Mac OS, Android, dan iOS beserta browser yang telah tersedia pada user seperti Google Chrome dan Mozila Firefox yang dimana keduanya harus sudah terupdate ke versi terbaru.

\section{Perancangan Sistem}

Perancangan SI PUAN menggunakan use case diagram, class diagram dan entity relation diagram.

1. Use Case Diagram

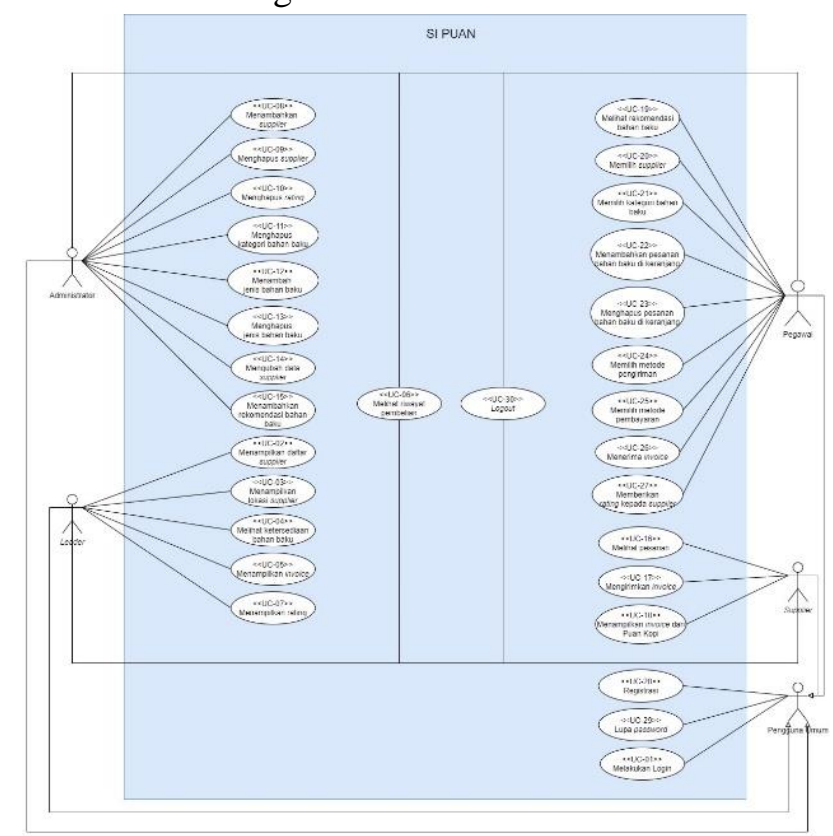

Gambar 2. Use Case Diagram
2. Class Diagram

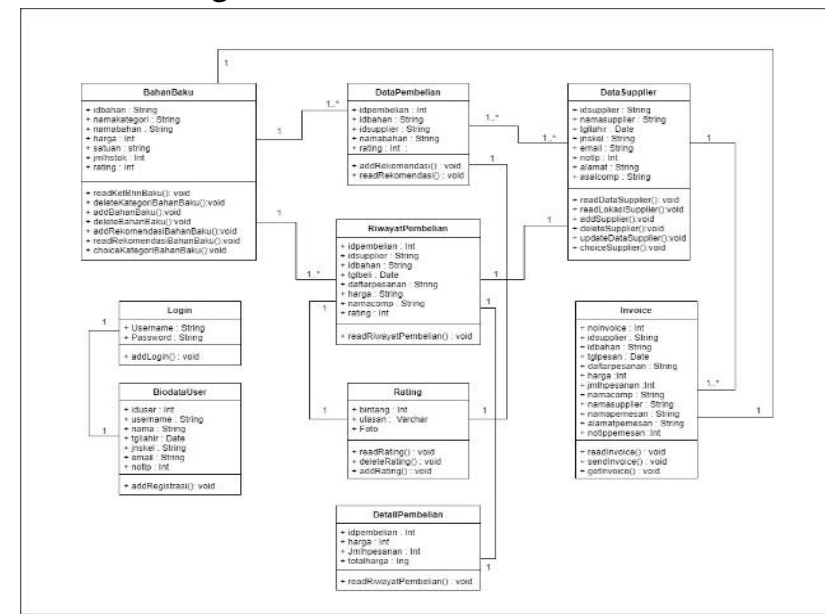

Gambar 3. Class Diagram

3. Entity Realation Diagram

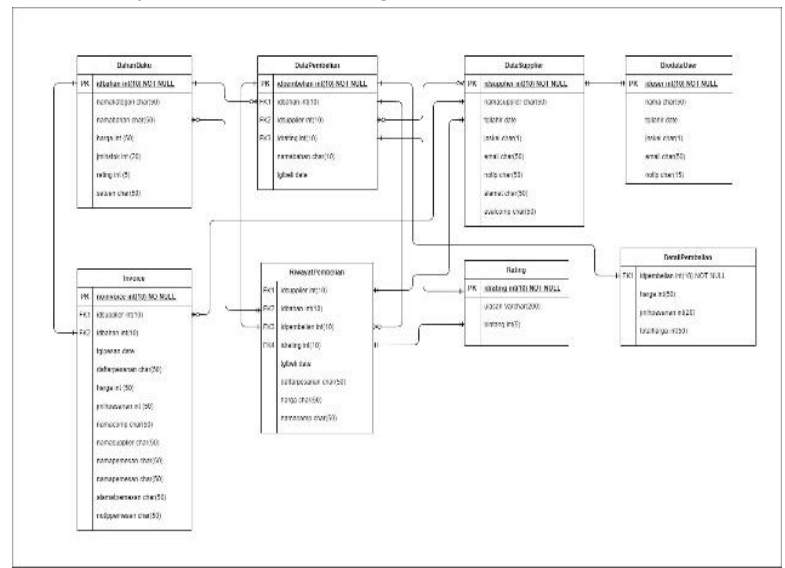

Gambar 4. Entity Realation Diagram

\section{Implementasi Desain dan Perancangan}

Pada tahap implementasi dan desain perancangan, website SI PUAN didapatkan hasil sebagai berikut:

1. Tampilan Login

Pada halaman login merupakan tampilan username dan password serta ada fitur lupa password untuk jika pengguna lupa.

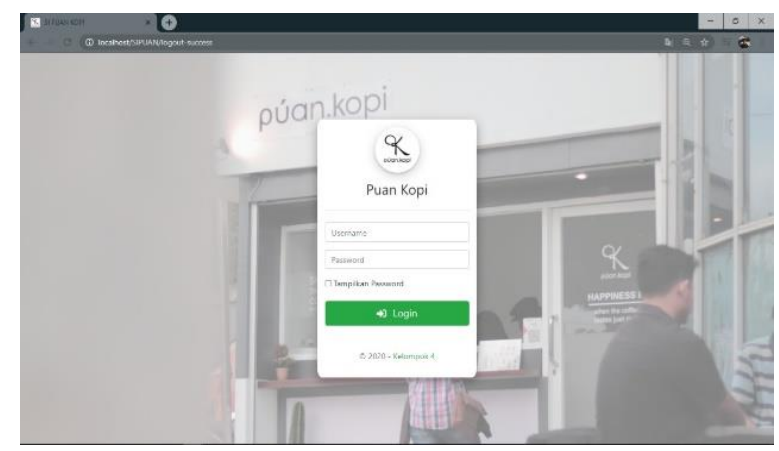

Gambar 5. Tampilan Login 
2. Tampilan Menampilkan Daftar Supplier Pada halaman supplier terdapat fitur untuk menambahkan supplier, kemudain melakukan edit supplier, serta menghapus supplier.

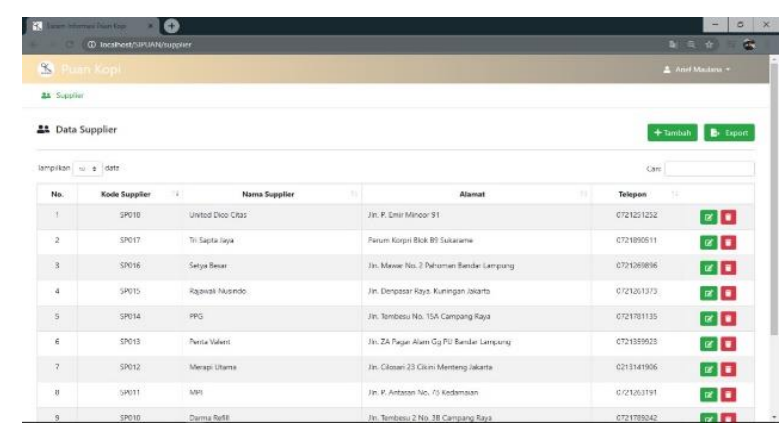

Gambar 6. Tampilan Menampilkan Daftar Supplier

3. Tampilan Menampilkan Lokasi Supplier

Pengguna dapat melihat lokasi para supplier yang memasok bahan baku di PUAN KOPI.

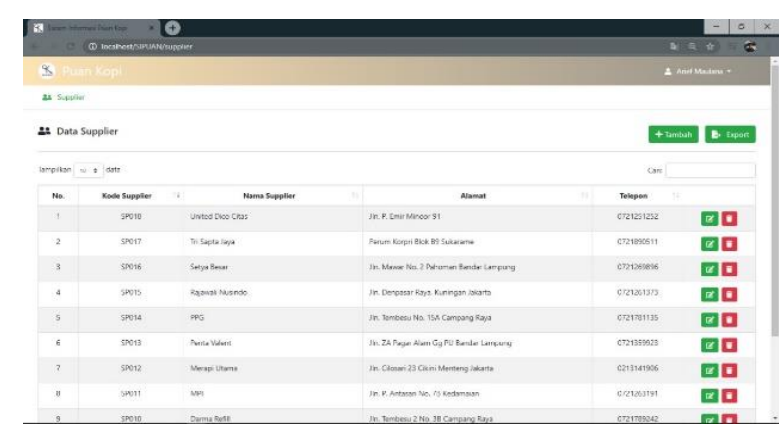

Gambar 7. Tampilan Menampilkan Lokasi Supplier

\section{Tampilan Registrasi}

Pengguna yang belum mendapatkan akun bisa melakukan registrasi akun dengan memasukkan nama, username, dan password. Pengguna baru menunggu persetujuan dari admin agar mendapatkan hak akses yang sesuai dengan peruntukannya.

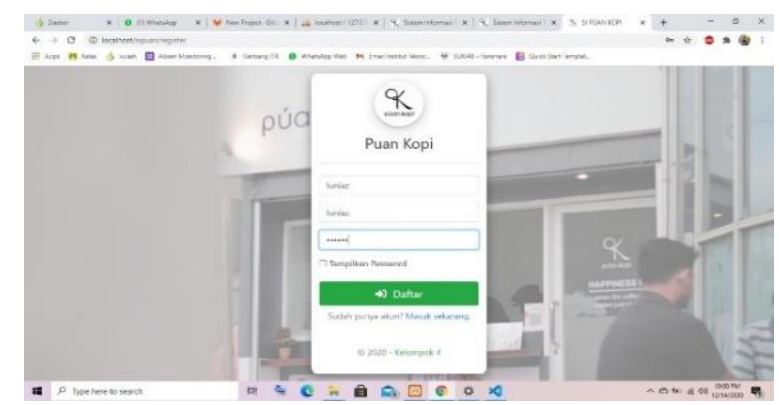

Gambar 8. Tampilan Registrasi
5. Tampilan Menambahkan Rekomendasi Bahan Baku

Berikut merupakan tampilan dari rekomendasi supplier bahan baku yang telah menyelesaikan proses pembelian. Supplier yang mendapatkan bintang lebih dari sama dengan 3 maka ditampilkan dalam halaman rekomendasi.

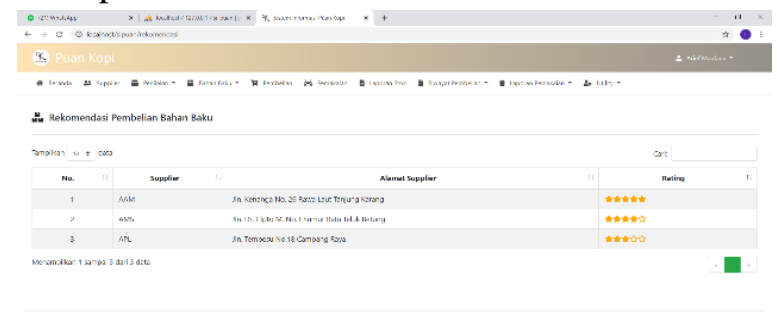

Gambar 9. Tampilan Menambahkan Rekomendasi Bahan Baku

\section{Tampilan Menampilkan Rating}

Berikut merupakan tampilan dari rating yang telah dinilai oleh pegawai kepada supplier. Rating ditampilkan setiap pembelian telah selesai dan rating serta feedback sudah diisi oleh pegawai.

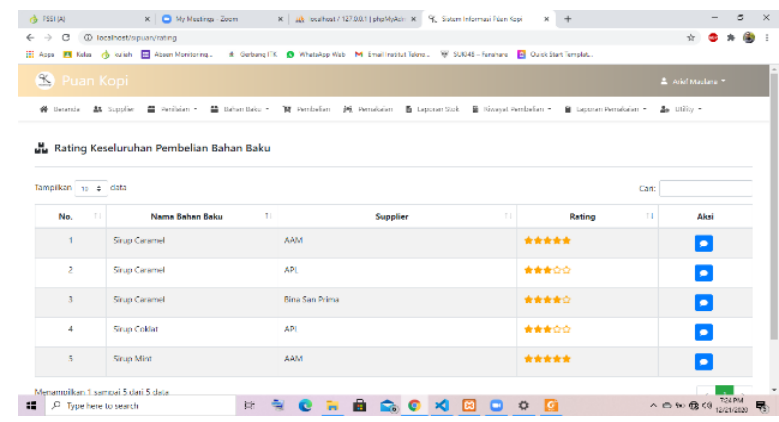

Gambar 10. Tampilan Menampilkan Rating

7. Tampilan Menghapus Rating

Rating dapat dihapus ketika pegawai salah memasukkan rating dan feedback kepada pegawai.

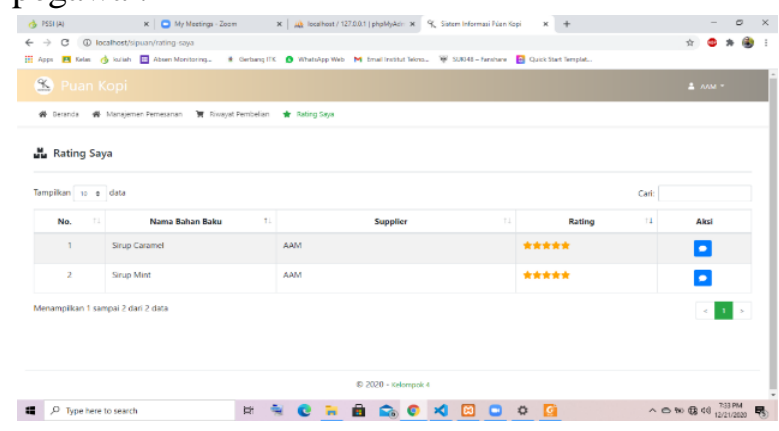

Gambar 11. Tampilan Menghapus Rating 
8. Tampilan Mengirimkan Invoice

Supplier melakukan konfirmasi ketika pembayaran yang dilakukan oleh PUAN KOPI telah berhasil masuk ke rekening supplier. Supplier memasukkan nomor nota dan jumlah uang yang masuk ke dalam rekening supplier.

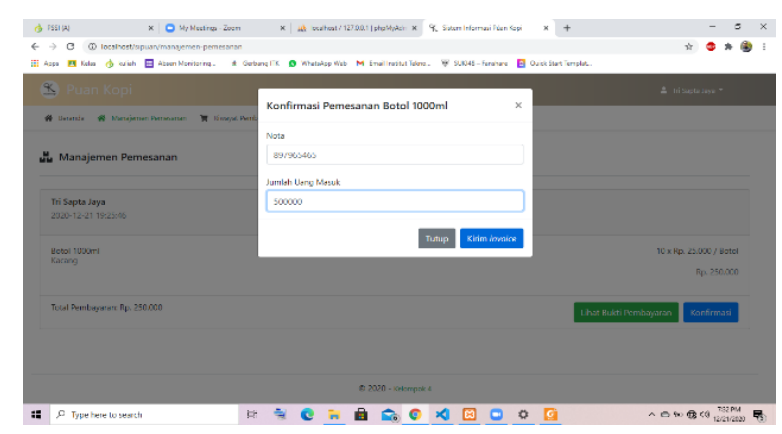

Gambar 12. Tampilan Mengirimkan Invoice

9. Tampilan Menampilkan Rating

Supplier dapat melihat rating yang telah diberikan oleh pegawai kepada setiap supplier yang telah mengirimkan bahan baku yang dipesan oleh PUAN KOPI.

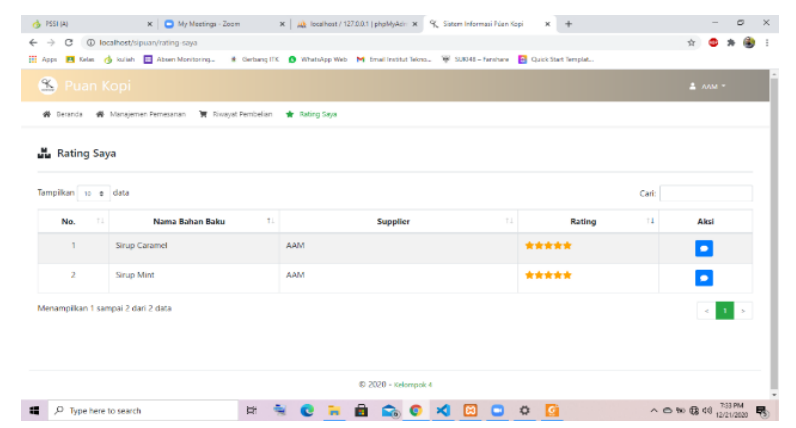

Gambar 13. Tampilan Menampilkan Rating

\section{Tampilan Melihat Invoice}

Pegawai dan admin melihat kuitansi pembelian yang telah selesai.

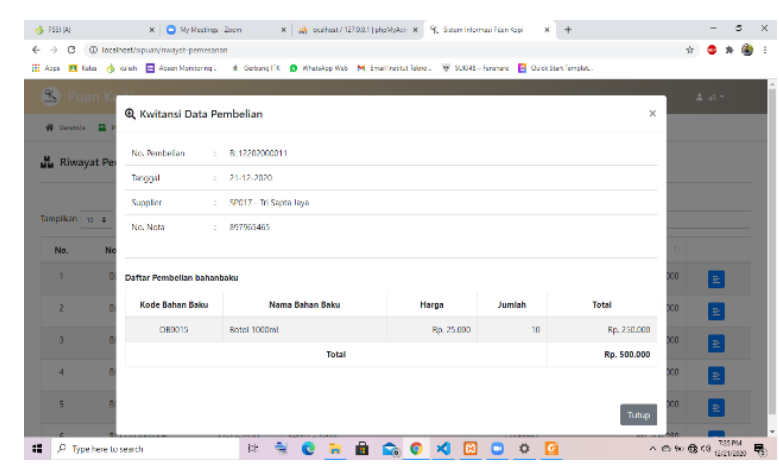

Gambar 14. Tampilan Melihat Invoice
11.Tampilan Memberikan Rating Kepada Supplier Pegawai memberikan rating dan feedback kepada supplier sebelum melihat kuitansi pemesanan yang telah selesai.

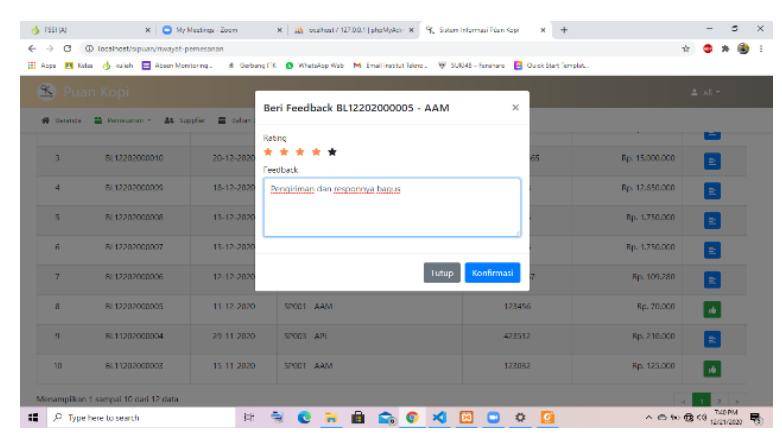

Gambar 15. Tampilan Memberikan Rating Kepada Supplier

\section{Pengujian Perangkat Lunak}

Tahap pengujian perangkat lunak berguna untuk mengetahui kemampuan dari program SI PUAN yang telah berhasil dirancang agar sesuai dengan rencana awal dan kebutuhan pengguna. Berikut merupakan flow graph pengujian perangkat lunak.

\section{Fitur View Supplier}

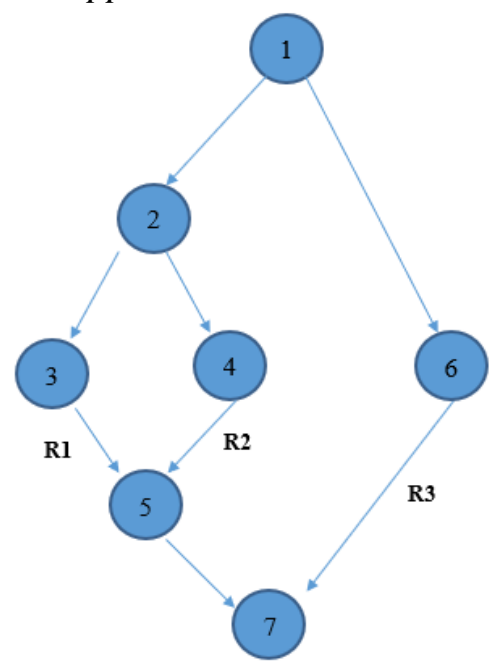

Gambar 16. Flow Graph Fitur View Supplier

Jalur Independen :

1) $1-2-3-5-7$;

2) $1-2-\underline{4}-5-7$

3) $1-\underline{6}-7$;

Perhitungan Cyclomatic Complexity / V(G) :

- $(\mathrm{G})=\mathbf{3}$ Region

- $\mathrm{V}(\mathrm{G})=\mathrm{E}-\mathrm{N}+2=8-7+2=\mathbf{3}$

- $\mathrm{V}(\mathrm{G})=\mathrm{P}+1=2+1=\mathbf{3}$ 
2. Fitur Riwayat Pembelian

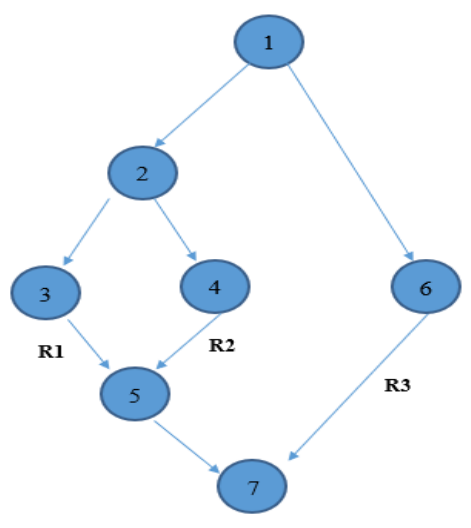

Gambar 17. Flow Graph Fitur Riwayat Pembelian

Jalur Independen :

1) $1-2-3-5-7$;

2) $1-2-\underline{4}-5-7$;

3) $1-\underline{6}-7$

Perhitungan Cyclomatic Complexity / V(G) :

- $(\mathrm{G})=\mathbf{3}$ Region

- $\mathrm{V}(\mathrm{G})=\mathrm{E}-\mathrm{N}+2=8-7+2=\mathbf{3}$

- $\mathrm{V}(\mathrm{G})=\mathrm{P}+1=2+1=\mathbf{3}$

3. Pengujian Akhir

Tabel 6. Pengujian Akhir

\begin{tabular}{l|c}
\hline \multicolumn{1}{c}{ No Req } & Status \\
\hline SRS_F-SI PUAN-008 & Valid \\
\hline SRS_F-SI PUAN-008 & Valid \\
\hline SRS_F-SI PUAN-008 & Valid \\
\hline SRS_F-SI PUAN-008 & Valid \\
\hline SRS_F-SI PUAN-012 & Valid \\
\hline SRS_F-SI PUAN-012 & Valid \\
\hline SRS_F-SI PUAN-012 & Valid \\
\hline SRS_F-SI PUAN-012 & Valid \\
\hline SRS_F-SI PUAN-015 & Valid \\
\hline SRS_F-SI PUAN-015 & Valid \\
\hline SRS_F-SI PUAN-022 & Valid \\
\hline SRS_F-SI PUAN-022 & Valid \\
\hline SRS_F-SI PUAN-022 & Valid \\
\hline SRS_F-SI PUAN-022 & Valid \\
\hline SRS_F-SI PUAN-027 & Valid \\
\hline SRS_F-SI PUAN-027 & Valid \\
\hline SRS_F-SI PUAN-027 & Valid \\
\hline SRS_F-SI PUAN-027 & Valid \\
\hline SRS_NF-SI PUAN-005 & Valid \\
\hline SRS_NF-SI PUAN-002 & Valid \\
\hline
\end{tabular}

\section{KESIMPULAN}

Berdasarkan hasil penelitian dan pengujian yang dilakukan, maka dapat diambil kesimpulan sebagai berikut:

1. Kebutuhan fungsional dari sistem informasi ini berjumlah 30 kebutuhan funsional.

2. Pengujian dilakukan dengan dua Teknik yaitu black box dan white box. White box testing dilakukan dengan pengujian basis bath pada 2 fitur yaitu view supplier dan riwayat, dan untuk pengujian black box dilakukan dengan cara pengujian validasi terhadap 20 kebutuhan fungsional dan hasilnya valid.

3. Sistem yang dirancang dan dibangun pada penelitian ini yaitu sistem informasi persediaan bahan baku. Sistem persediaan bahan baku dapat menunjang kegiatan bisnis Puan Kopi secara berkelanjutan dengan mengontrol jumlah persedian bahan baku sesuai kebutuhan yang diperlukan.

\section{DAFTAR PUSTAKA}

Andika, D. (2016). IT-JURNAL.com. Retrieved Desember 30, 2020, from https://www.itjurnal.com/pengertian-rekayasa-perangkatlunak/

Anggraeni, E. Y., \& Irviani, R. (2017). Pengantar Sistem Informasi. Yogyakarta: CV Andi Offset.

Anwar, A. S. (2018). Penerapan E-Supply Chain Management Dalam Upaya Peningkatan Produktifitas dan Pemasaran Produk pada Industri Rumah Tangga dalam Persaingan di Era Teknologi Informasi. Jurnal Teknologi dan Sistem Informas, 4, 185-190.

Astuti, P., Wafa, M. A., \& Marie, I. A. (2018). Perancangan Sistem Informasi Perencanaan dan Pengendalian Persediaan Bahan Baku di PT. X. Jurnal Teknik Industri, 172-187.

Batubara, F. A. (2012). Perancangan Website Pada PT. Ratu Enim Palembang. Jurnal Ilmu Pengetahuan dan Teknologi Terapan, 7 (1), 17.

Christia, \& Surjasa, D. (2017). Sistem Informasi Perencanaan dan Pengendalian Persediaan Bahan Baku Di PT X. Jurnal Teknik Industri, 136-150. 
Dr. Ratna Wardani, S. M. (2012). Rekayasa Perangkat Lunak. Yogyakarta: Tim UNY.

Haviluddin. (2011). Memahami Penggunaan UML (Unified Modelling Language). Jurnal Informatika Mulawarman, 6 (1).

Mumtahana, D. Y. (2019). Rancang Bangun Sistem Informasi Pengendalian Persediaan Barang dengan Metode Economic Order Quantity (EOQ) Berbasis Dekstop Dengan Menggunakan Java Netbeans 8.2 pada Wijaya Celluler. Seminar Nasional Teknologi Informasi dan Komunikasi, 229.

Nia Kumaladewi, M. C. (2015). Rancang Bangun Sistem Infromasi Pengendalian Persediaan Bahan Baku dan Hasil Produksi Pada PT. Gemilang Sinergitama Mandiri. Jurnal Sistem Informasi, 8(2), 4.

Saputra, A. (2012). Manajemen Basis Data MySQL Pada Situs FTP Lapan Bandung. Berita Dirgantara, 13 (4), 155-157.

Suhartanto, M. (2012). Pembuatan Website Sekolah Menengah Pertama Negeri 3 Delanggu. Journal Speed - Sentra Penelitian Engineering dan Edukasi, 4 (1), 2.

Sulistyorini, P. (2009). Pemodelan Visual dengan Menggunakan UML dan Rational Rose. Jurnal Teknologi Informasi DINAMIK, XIV (1), 23-24.

Tuerah, M. C. (2014). Analisis Pengendalian Persediaan Bahan Baku Ikan Tuna Pada Cv. Golden Kk. Jurnal EMBA, 2 (4), 526. 